\title{
ESTUDO DE CASO DISCUTIDO À LUZ DAS DIFERENTES ABORDAGENS PARA A TERAPIA DA GAGUEIRA
}

\author{
Case study discussed under the light of different \\ stuttering therapy approaches
}

\author{
Larissa Severa da Silva ${ }^{(1)}$, Maria Inês Dornelles da Costa Ferreira (2)
}

\begin{abstract}
RESUMO
Tema: na atualidade, a gagueira pode apresentar definições distintas de acordo com a abordagem defendida pelos autores para fundamentar tal distúrbio. $O$ trabalho tem como objetivo discutir tais abordagens na terapia do caso em questão, aplicando suas técnicas terapêuticas e adequando-as conforme o contexto em questão e a aceitação do indivíduo para com as atividades, promovendo o desenvolvimento dos objetivos, procedimentos e técnicas utilizados na terapêutica para a gagueira. Procedimentos: estudo longitudinal de um paciente de 14 anos, atendido em dois momentos: entre 2005/2006, ano em que recebeu alta com indicação de monitoramento, e 2008/2009 época em que retorna ao atendimento devido à recidiva. No estudo, são consideradas as diferentes abordagens: psicolinguística da fluência, neurolinguística e motora da gagueira, vertente contextualizada e abordagem fenomenológica da gagueira. Resultados: na evolução, observou-se a diminuição considerável da gagueira e dos movimentos compensatórios, bem como, comportamento e postura adequados e uma melhor socialização. Conclusão: o estudo das abordagens consideradas na terapia propiciou a realização do atendimento que atingiu os objetivos propostos. Além disso, o paciente contribuiu no direcionamento da terapia conforme sua aceitação e aplicação em sua vida, revelando, dessa forma, quais condutas foram mais efetivas e puderam contribuir de forma mais direta com a sua qualidade de vida e sua evolução.
\end{abstract}

DESCRITORES: Gagueira; Terapia da Linguagem; Linguagem; Fonoterapia; Estudo de Caso; Comunicação

\section{INTRODUÇÃO}

A gagueira pode ser definida de diversos modos segundo diferentes autores. Devido à dificuldade de especificar a etiologia desse fenômeno alguns autores desenvolveram abordagens teóricas para lidar com esse distúrbio. A partir disso serão citadas as abordagens que servirão de apoio e direção para a terapia fonoaudiológica do caso apresentado

(1) Fonoaudióloga; Graduada pelo Centro Universitário Metodista IPA - Porto Alegre/RS, Brasil.

(2) Fonoaudióloga; Professora do Curso de Fonoaudiologia do Centro Universitário Metodista IPA - Porto Alegre (RS), Brasil; Doutora em Linguística Aplicada pela Pontifícia Universidade Católica do Rio Grande do Sul.

Este trabalho foi realizado na Clínica Exército da Salvação, localizada em Porto Alegre/RS, Brasil.

Conflito de interesses: inexistente nesse estudo. São elas: abordagem psicolingüística da fluência ${ }^{1}$, abordagem neurolinguística e motora da gagueira ${ }^{2}$, abordagem na vertente contextualizada - análise de discurso ${ }^{3}$ e abordagem fenomenológica da gagueira ${ }^{4}$.

A abordagem psicolingüística da fluência considera a definição de gagueira como rupturas na fala espontânea sendo estas no nível da palavra apresentando repetições, prolongamentos e bloqueios ${ }^{1}$, podendo ser acompanhados de movimentos corporais e/ou faciais ${ }^{5}$. A teoria apóia-se em modelo de produção de fala que ocorre em três etapas: 1) etapa do contextualizador: há intenção de comunicar; mensagem pré-verbal; 2) etapa do formulador: a mensagem é codificada em parâmetros gramaticais e sintáticos e, posteriormente, em parâmetros fonológicos; 3) etapa do articulador - a mensagem é transmitida do plano articulatório ou 
fonético para o sistema neuromuscular, sendo finalmente executada ${ }^{1}$. A terapia consiste em trabalhar as habilidades de fala: respiração, fonação, articulação e prosódia 5 .

Tal abordagem relaciona a gagueira e o processamento auditivo ${ }^{6}$. Após realizar pesquisa sobre 0 tema, constatou-se comprometimento do processamento auditivo, alterado em $92,85 \%$ da população pesquisada sendo a categoria do processo gnósico não verbal destacada por ser a mais alterada ${ }^{7}$. O resultado pode ser explicado pelo ao fato dos indivíduos gagos não possuírem dominância hemisférica para a fala podendo ter dominância invertida ou possuírem dominância bilateral, apresentarem anormalidades anatômicas cerebrais, assimetria do lobo temporal, irregularidades periódicas na temporalização dos movimentos de fala ou alteração nos padrões temporais motores e sensoriais ${ }^{6}$.

Em outro estudo, concluiu-se que o desempenho da orelha direita foi melhor em comparação à orelha esquerda cujo resultado refere-se às diferentes funções de cada hemisfério cerebral relacionadas ao desempenho de cada orelha em testes dicóticos ${ }^{7}$. Tal achado pode ter corroborado em outro estudo em que a autora comparou os resultados pré e pós tratamento por meio dos potenciais evocados auditivos (P300) constatando que houve melhora na amplitude da onda na orelha direita na redução das sílabas gagas. Sugere, ainda, que para esses indivíduos após o tratamento parece ocorrer maior ativação do hemisfério esquerdo ${ }^{8}$. Não houve relação da gravidade da gagueira com as manifestações do distúrbio do processamento auditivo ${ }^{6}$.

A literatura internacional aponta que o processamento de fala nas pessoas que gaguejam resulta de alterações no input auditivo. Uma pesquisa examinou as mudanças funcionais e estruturais no córtex auditivo das pessoas que gaguejam e identificou um déficit no hemisfério esquerdo e expansão da organização tonotópica no hemisfério direito ${ }^{9}$. Outro estudo de caso revelou que os déficits mais frequentes na bateria de avaliação comportamental do processamento auditivo encontravam-se relacionados aos testes de integração binaural e de processamento temporal ${ }^{10}$.

A abordagem neurolinguística e motora da gagueira cita a característica multidimensional da gagueira, cuja origem também se encontra no déficit do processamento cortical ${ }^{11}$. Além das rupturas características no fluxo da fala é considerada a experiência do indivíduo frente suas reações nas diversas situações enfrentadas, assim como sua participação nas atividades de vida diária e o impacto gerado na qualidade de vida desse indivíduo². Em pesquisa realizada com indivíduos gagos com diferentes graus de gravidade, observou-se que os sujeitos de grau leve apresentavam igual perfil afetivo, comportamental e cognitivo dos sujeitos de graus mais graves afetando negativamente a qualidade de vida, gerando frustração e revelando que os mesmos se detêm mais na forma do que no conteúdo da fala ${ }^{12}$. Em contrapartida, outro estudo mostrou uma correlação positiva entre o grau de severidade da gagueira e o impacto da mesma na qualidade de vida ${ }^{13}$.

Em relação aos aspectos lingüísticos, espera-se que o indivíduo tenha a capacidade de selecionar as palavras e formar as sentenças mais apropriadas socialmente e, ainda, fonologicamente corretas para atender às demandas geradas pelo meio social em que o sujeito vive. Nos aspectos motores a movimentação do trato vocal deve ser rápida pela organização entre os vários movimentos e o tempo para realizá-los, exigindo a coordenação dos processos neurais e mecanismos sensório-motores, numa atuação suave e sem fracionamento gerando o discurso fluente ${ }^{14}$.

Outro estudo realizado com gagos e fluentes verificou como funciona a ativação muscular nas tarefas de fala e não-fala, em que os indivíduos fluentes apresentam prontidão do sistema motor para a fala, porém o mesmo não ocorre nos gagos. Esse fato pode ser consequente de uma desorganização na temporalização entre os processamentos cerebrais e motores envolvidos na fala, ocorrendo em latências maiores ao iniciar uma verbalização favorecendo 0 aparecimento das disfluências ${ }^{15}$. Vários estudos apontam para um déficit no planejamento e na execução motora da pessoa que gagueja e como tais diferenças afetam a maneira de falar ${ }^{16,17,18}$. A terapia proposta se divide em duas fases sendo a primeira de utilização de técnicas de relaxamento corporal, respiração, voz, motricidade orofacial, e uso de técnicas específicas, como prática negativa, suavização dos movimentos iniciais e disfluências voluntárias visando a promoção da fluência. Já na segunda fase objetiva-se a manutenção da fluência adquirida, o aumento da velocidade de fala, a valorização do padrão adquirido, o controle sobre a fala e o uso do telefone ${ }^{5}$.

$\mathrm{Na}$ abordagem da vertente contextualizada análise do discurso a autora faz uma relação em que a gagueira apresentada durante a produção da fala é decorrente do contexto psicológico, afetivo, cognitivo em que o indivíduo se encontra no momento em que fala, aparecendo de modo imprevisível por motivos que competem à subjetividade do mesmo. O terapeuta se relaciona não somente com o objetivo (a gagueira), mas principalmente com o aspecto subjetivo, a imagem que o mesmo possui sobre si diante da gagueira ${ }^{19}$. 
O propósito da terapia se dá em ressignificar a imagem que o indivíduo tem de si como sujeito falante, pois o mesmo pode vir a apresentar uma das seguintes situações: 1) O sujeito é visto como gago somente pelos outros, assim sendo, a consciência do sujeito sobre a própria gagueira é baixa, sendo imperceptível para o mesmo; 2) O indivíduo se vê e é visto gago, tendo plena consciência da sua disfluência; 3) Somente o indivíduo se percebe como sendo gago, havendo uma distorção da autoimagem e supervalorização da fluência. Para trabaIhar com a auto-imagem do sujeito gago objetivase conhecer os recursos utilizados para evitar a gagueira e as suas tentativas de falar bem sensibilizando o paciente para que perceba a tensão realizada, promovendo assim, a consciência corporal ${ }^{5}$.

Por fim, a abordagem fenomenológica da fluência não propõe uma definição para a gagueira, pois cada indivíduo terá uma descrição particular para a materialização da mesma, manifestada em seu corpo, porém afetando sua visão sobre si, sobre seu problema e sobre o mundo ${ }^{4}$ Para isso, é necessário que o terapeuta descreva o que percebe, em relação aos movimentos musculares, à tensão, à velocidade, ao ritmo de fala, à coordenação do fluxo de ar. Ao perceber-se como sujeito gago as impressões, os sentimentos e a aceitação que o mesmo possui em relação à gagueira devem ser considerados. A terapia terá como objetivo a "desconstrução da gagueira", promovendo o controle do tônus muscular, realizando um trabalho de conscientização da gagueira, relacionando-a às emoções, ao nível de interferência que ocorre na fluência e às reações do sujeito diante da patologia ${ }^{5}$.

O presente trabalho objetivou a discussão das abordagens apresentadas na condução do caso em questão.

\section{APRESENTAÇÃO DO CASO}

J. O. iniciou o atendimento aos 9 anos de idade quando estava na 4⿳亠丷a série do Ensino Fundamental, no primeiro semestre de 2005. Segundo informações coletadas do seu prontuário, J. apresentou atraso no desenvolvimento da linguagem, pronunciando as primeiras palavras somente aos dois anos de idade. Realizou acompanhamento neurológico devido a este atraso. No exame de Eletroencefalografia (EEG) realizado em 04/12/1998 em sono normal ( $3^{\circ}$ estágio), constatou-se em vigília, ritmo de base lento nas áreas posteriores do encéfalo. Iniciou tratamento com carbamazepina, durante aproximadamente um ano e seis meses. Após este período realizou novos exames de EEG em 09/05/2000 e 31/05/2000 não apresentando anormalidades.
Aos dois anos e seis meses realizou atendimento fonoaudiológico devido a dificuldades na fala. Segundo relato da mãe, falou corretamente aos cinco anos e no ano seguinte apresentou os primeiros sinais de disfluência.

$\mathrm{Na}$ anamnese realizada na época, a mãe mencionou que o paciente apresentava comportamento disciplinado, prestativo, de temperamento calmo e distraído. Relacionava-se bem com todos os familiares e com colegas de escola. Referiu, ainda, que o menino era um bom aluno e não apresentou dificuldades de leitura e escrita, porém destacou o histórico de gagueira na família (tio do paciente) e de intercorrências na escola (pai do paciente). No mesmo momento, a mãe informou a ocorrência de um quadro de otites de repetição, bem como a realização de adenotonsilectomia.

Após a da entrevista inicial o paciente realizou avaliação fonoaudiológica em que foram descartados intercorrências de ordem fonológica e de aprendizado.

J. realizou avaliação do Processamento Auditivo Central $(\mathrm{PA}(\mathrm{C}))$ revelando alterações nos subperfis de organização de saída, decodificação e integração.

A terapia fonoaudiólogica, nesse primeiro momento, teve enfoque nos aspectos de correção da postura, respiração, movimentos compensatórios realizados durante a gagueira e exercícios de articulação.

Neste período foi observado redução dos movimentos compensatórios e o início de um processo de socialização do paciente, em que fora relatada sua participação em grupo de jovens, realizando leituras com redução da disfluência e participando ativamente das atividades, uma vez que o mesmo apresentava traços de inibição e isolamento em conseqüência da sua gagueira.

Em função de realizar atendimento em um dos locais da clínica escola o paciente passou a ser atendido por uma nova estagiária no início do ano de 2006.

A partir desse momento a terapia fonoaudiológica passou a ser realizada enfatizando o transtorno do $\mathrm{PA}(\mathrm{C})$ apresentado por J., (além da manutenção da terapia para a gagueira. Após aproximadamente seis meses realizou-se nova avaliação do $P A(C)$ constatando-se que o funcionamento auditivo central encontrava-se nos padrões de normalidade para a idade.

Ao final do semestre de 2006 foi prescrita uma indicação de monitoramento, em que o paciente deveria apresentar-se na clínica quinzenalmente. Para o início do ano de 2007 foi indicado um encontro por mês com objetivo de evitar recidivas, porém o mesmo não retornou a esses atendimentos. 
Em setembro de 2008 o paciente retorna para terapia fonoaudiológica, relatando involução acentuada na gagueira.

Nesta data o paciente encontrava-se com 12 anos e cursando a $7^{\text {a }}$ série do Ensino Fundamental.

$\mathrm{Na}$ avaliação fonoaudiológica verificaram-se os achados de uma possível hiperconstrição laríngea, gerando uma qualidade vocal tensa, resultados obtidos por meio dos tempos máximos de fonação. Reafirmando esse achado, a média das vogais /a/, /e/ e /i/, sugerem tensão em todo o mecanismo de fala. O que é percebido durante sua fala normal. Além disso, observou-se modo respiratório oronasal e tipo superior. Conforme o relato da mãe, o paciente apresenta rinite e asma, ficando constantemente congestionado. Não possui uma postura adequada, apóia-se na mesa deitando a cabeça sobre o braço; em pé escora-se na parede ou fica se movimentando. Apresenta um comportamento tímido e retraído. Não gosta de falar e normalmente responde às perguntas com uma palavra ou com frases curtas. $\mathrm{Na}$ avaliação da leitura apresentou poucos momentos de gagueira, sendo eles bloqueios e algumas repetições de sílabas.

De acordo com os aspectos mencionados verificou-se uma mudança de comportamento do paciente nesse retorno em comparação aos atendimentos anteriores, talvez devido ao início da adolescência.

O tratamento, nesse segundo momento, objetivou amenizar a gagueira deixando a fala do paciente mais fluente. Como objetivos específicos destacam-se: 1) Redução da tensão no mecanismo da fala: Em que o paciente realizava muito esforço, mantendo o pescoço rígido e dificuldade na articulação das palavras; 2) Aumento dos tempos máximos de fonação; 3) Melhora da articulação e da respiração, em que o paciente apresentava uma articulação limitada, dificultando a compreensão dos fonemas realizados, sendo assim o paciente realizava frases curtas, com a intensidade da voz diminuída; 4) Trabalho com os aspectos linguísticos como a prosódia que se encontrava bastante alterada devido à articulação pobre; a clareza na produção dos fonemas, a velocidade da fala demasiadamente rápida; e também em contextos de ordem subjetiva como a intenção de se comunicar, apesar dos momentos de disfluência; 5) Posicionamento como um sujeito falante.

No primeiro momento desta última intervenção não foi aplicada nenhuma técnica específica para a gagueira. Utilizaram-se exercícios de relaxamento, alongamento e articulação com o objetivo de aliviar a tensão do mecanismo de fala ${ }^{2,11}$. Devido à timidez do paciente e a dificuldade de se expor, a avaliação tornou-se mais complicada e menos precisa. Constataram-se suas maiores dificuldades na fala espontânea, por meio das frases curtas que emitia, utilizando uma palavra-apoio ao iniciar frases, na tentativa de inibir a disfluência e fuga do tópico quando o enfoque relaciona-se à gagueira e demais aspectos ligados à terapia.

Como já mencionado, o paciente é um adolescente tímido e retraído, com isso demonstrou dificuldades no início do atendimento, pois não gostava de falar sobre sua gagueira, limitava-se a responder às perguntas com uma ou duas palavras, dificultando também a avaliação.

O presente estudo de caso foi desenvolvido a partir de um projeto de pesquisa mais amplo, aprovado pelo Comitê de Ética em Pesquisa do Centro Universitário Acadêmico - IPA sob o Protocolo no 123/2008.

\section{RESULTADOS}

Após o estabelecimento do vínculo terapeuta e paciente, o mesmo conseguiu se expressar melhor ficando mais à vontade para conversar utilizando menos recursos para evitar a gagueira. Nesse caso, o paciente se via e era visto como gago. A interação discursiva priorizou a apreensão da subjetividade em relação à sua imagem de falante ao compreender as diferenças entre a fala fluente e disfluente e aos poucos abandonar as estratégias para evitar a gagueira ${ }^{3,4,19}$. Assim, o paciente apresentou uma pequena evolução, sendo percebida em terapia e reconhecida pelos seus pais.

Os exercícios de relaxamento, articulação e respiração repercutiram no aumento dos tempos máximos de fonação do paciente ${ }^{1,2,12,15}$. Além disso, a realização de atividades de jogos de conhecimentos gerais contribuiu para que o paciente participasse mais efetivamente da terapia, diminuindo sua timidez, falando mais e mostrando suas capacidades e conhecimentos. A partir desse momento foi possível a realização de uma filmagem em atendimento, gravada em DVD em que o paciente assistiu primeiramente sozinho em casa e após, durante a terapia, permitindo que o mesmo avaliasse a sua gagueira e percebesse seus momentos de tensão, a voz fraca, a velocidade de fala aumentada, o uso de uma palavra-apoio para iniciar frases e sua postura. Com essa atividade o paciente conscientizou-se desses pontos e procurou monitorar-se.

Posteriormente, o paciente apresentou sinais de abandono da terapia, demonstrando pouco interesse nas atividades propostas.

A partir disso, a terapia buscou esclarecer pontos como anatomia e fisiologia dos órgãos ligados à produção da fala, além da abordagem sobre a 
mudança de postura em relação ao tratamento e conversa com os pais.

Os pais relatam uma mudança de comportamento na escola. J. que sempre foi um bom aluno começou a apresentar notas baixas e queixas dos professores de mau comportamento em sala de aula. Os pais referem que essa mudança pode estar ligada à nova rotina de J., início de cursinho preparatório para escola militar e academia todas as tardes durante a semana.

J. mostrou seu desejo em continuar a terapia a partir da conscientização sobre a importância do tratamento. Devido à aproximação do período de férias, formulou-se uma tabela de exercícios para controle de respiração com consoantes fricativas, emissão de palavras e de frases com o objetivo de promover a coordenação pneumofonoarticulatória e suavizar os movimentos iniciar promovendo a fluência ${ }^{1,2,12,15}$.

No retorno das férias foi percebida uma postura corporal mais adequada, aprimorada nas suas atividades físicas diárias. O comportamento de J. tornouse inconstante. Em alguns encontros mostrou-se disposto e interessado nas atividades propostas em contraponto aos dias em que se apresentava indiferente ao tratamento. Percebeu-se que na maior parte do tempo o comportamento do paciente foi sempre inconstante, variando entre momentos de colaboração e interesse na terapia e os momentos de distanciamento e desinteresse, porém deixando claro suas preferências na terapia.

Nos quadros seguintes são apresentados os dados considerados de maior expressividade e importância das avaliações realizadas nos atendimentos anteriores (figura 1) e a reavaliação do paciente no atendimento atual (figura 2), realizada pela primeira autora do estudo:

O paciente avaliou-se utilizando um questionário, sendo esse o meio encontrado para suprir a dificuldade demonstrada pelo paciente em comunicar seus sentimentos em relação à terapia e à gagueira apresentada. O questionário continha 10 perguntas com respostas objetivas.

O paciente, nesse período, já se encontrava mais fluente, considerou que a gagueira não prejudicou significantemente sua vida e seus relacionamentos, porém refere que seria mais feliz não gaguejando, deixando em algumas ocasiões de realizar algo que gostaria em função da gagueira. Acredita ser ele o maior prejudicado pela gagueira, porém não se sente inferior em relação às outras pessoas e não sente que o tratem com preconceito.

\begin{tabular}{|c|c|c|}
\hline Avaliações Anteriores & 2005 & 2006 \\
\hline Avaliação da Fluência & $\begin{array}{l}\text { Não realizada avaliação de leitura. } \\
\text { - Má coordenação pneumo- } \\
\text { fono-articulatória; } \\
\text { - respiração curta, } \\
\text { - velocidade de fala diminuída; } \\
\text { - articulação imprecisa, } \\
\text { movimenta a boca para a direita } \\
\text { e o queixo para frente ao } \\
\text { gaguejar; } \\
\text { - pouca movimentação vertical } \\
\text { da mandíbula; } \\
\text { - lábios e bochechas } \\
\text { hipotônicos; } \\
\text { - Presença de palavra-apoio } \\
\text { ao iniciar frases. }\end{array}$ & $\begin{array}{l}\text { Disfluências apresentadas em } \\
\text { avaliação da leitura: } \\
\text { - } 3 \text { repetições de sílaba } \\
\text { - } 4 \text { repetições de sons } \\
\text { - } 2 \text { prolongamentos } \\
\text { - } 3 \text { bloqueios } \\
\text { Apresentou ainda: } \\
\text { - Comportamento sociável; } \\
\text { - bom rendimento escolar; } \\
\text { - interessado na terapia; } \\
\text { - empenhado em realizar as } \\
\text { atividades propostas. }\end{array}$ \\
\hline $\begin{array}{l}\text { Avaliação dos Tempos } \\
\text { Máximos de Fonação }\end{array}$ & Não realizada. & Não realizada. \\
\hline Processamento Auditivo & $\begin{array}{l}\text { Resultados alterados nas tarefas } \\
\text { de Decodificação, Integração e } \\
\text { Organização de saída. }\end{array}$ & Resultados normais para a idade. \\
\hline
\end{tabular}

Figura 1 - Aspectos relevantes apresentados na avaliação dos anos de 2005 e 2006 


\begin{tabular}{|c|c|c|}
\hline Reavaliação & 2008 & 2009 \\
\hline Avaliação da Fluência & $\begin{array}{l}\text { Não realizada avaliação de leitura. } \\
\text { - Tipo respiratório superior e } \\
\text { modo oronasal; } \\
\text { - tensão no mecanismo de } \\
\text { fala; } \\
\text { - velocidade de fala } \\
\text { aumentada; } \\
\text { - postura inadequada; } \\
\text { - comportamento tímido e } \\
\text { retraído; } \\
\text { - emissão de palavra-apoio em } \\
\text { início de frase; } \\
\text { - evitação da gagueira por } \\
\text { respostas curtas. }\end{array}$ & $\begin{array}{l}\text { Disfluências apresentadas em } \\
\text { avaliação da leitura: } \\
\text { - } 2 \text { repetições de sílaba } \\
\text { - } 3 \text { repetições de palavras } \\
\text { Apresentou ainda: } \\
\text { - Postura adequada; } \\
\text { - respiração nasal; } \\
\text { - velocidade de fala } \\
\text { aumentada; } \\
\text { - articulação adequada; } \\
\text { - ausência de movimentos } \\
\text { compensatórios; } \\
\text { - diminuição da presença da } \\
\text { palavra-apoio ao iniciar um } \\
\text { diálogo. }\end{array}$ \\
\hline $\begin{array}{l}\text { Avaliação dos Tempos } \\
\text { Máximos de Fonação }\end{array}$ & $\begin{array}{l}\text { Tempos máximo de fonação: } \\
\text { /a/ }-12 \mathrm{~s} \\
/ \mathrm{i} /-9 \mathrm{~s} \\
/ \mathrm{u} /-10 \mathrm{~s} \\
\text { Relação } \mathrm{s} / \mathrm{z}-0,7\end{array}$ & $\begin{array}{l}\text { Tempos máximo de fonação: } \\
\text { /a/ }-20 \mathrm{~s} \\
/ \mathrm{i} /-18 \mathrm{~s} \\
/ \mathrm{u} /-19 \mathrm{~s} \\
\text { Relação } \mathrm{s} / \mathrm{z}-1,6\end{array}$ \\
\hline Processamento Auditivo & Não realizada esta avaliação. & $\begin{array}{l}\text { Funcionamento no padrão de } \\
\text { normalidade para a idade, porém } \\
\text { com rebaixamento de resolução } \\
\text { temporal na OE, (teste GIN). O } \\
\text { mesmo não era realizado na } \\
\text { época da primeira avaliação. }\end{array}$ \\
\hline
\end{tabular}

Figura 2 - Aspectos relevantes apresentados na avaliação dos anos de 2008 e 2009

\section{DISCUSSÃO}

São diversas as teorias propostas para o trabalho com a gagueira cuja etiologia é controversa e envolve os seguintes fatores: hereditário, psicológico, ambiental, contextual e inato ${ }^{5,20}$. No paciente em estudo, identifica-se o componente hereditário, característica referida nas abordagens psicolingüística da fluência e neurolinguística e motora da gagueira ${ }^{1,2}$. O pai do paciente apresentou dificuldades escolares e comportamento agitado, não sendo medicado, porém, com o passar do tempo, os sintomas desapareceram. $\mathrm{O}$ tio de $\mathrm{J}$. também apresenta gagueira. Além das questões hereditárias, o paciente necessitou de medicação (carbamazepina) e acompanhamento neurológico, pois segundo o relato da mãe, caso não recebesse tratamento poderia apresentar dificuldades escolares. O mesmo já apresentava tais sintomas devido ao atraso do desenvolvimento da linguagem necessitando de atendimento fonoaudiológico. De acordo com a medicação utilizada e com o relato pouco preciso da mãe, suspeita-se que o menino apresentava epilepsia.

A gagueira pode ser: adquirida ou neurogênica, do desenvolvimento ou idiopática e psicogênica ${ }^{2}$. O tipo adquirido manifesta-se em indivíduos fluentes que sofrem um dano cerebral, transtornos neurológicos entre outros ${ }^{2}$.

Outra hipótese que condiz com o caso seria a gagueira do desenvolvimento, que se inicia em torno do $2^{\circ}$ ano de vida e pode estender-se até a puberdade, podendo desaparecer conforme se processa a maturação cerebral. A literatura internacional aponta que $80 \%$ dos casos são de origem desenvolvimental e podem estar correlacionados a déficits atencionais e de memória para a resposta ao estímulo auditivo ${ }^{20,21}$. Dependendo da gravidade do caso e da presença de fatores associados a gagueira poderá perpetuar-se ${ }^{22}$.

A gagueira pode ser definida como produto de uma disfunção do sistema nervoso central com base genética. De acordo com este conceito e com o histórico do paciente, é possível que J. tenha herdado a gagueira, porém pelo fato do paciente 
encontrar-se no início da adolescência, tornou-se possível minimizar, consideravelmente, as manifestações do distúrbio. O ambiente familiar em que o paciente se encontra inserido aparenta ser tranqüilo. Nota-se o apoio da família em relação à terapia, na qual os pais engajaram-se e seguiram as orientações referentes ao tratamento do filho, não sendo observado no paciente ou nos familiares influências de implicações psicológicas importantes que viessem a interferir no atendimento e no trato com o paciente. Não foi relatado nenhum evento de cunho psicológico e/ou traumático que pudesse ter desencadeado o início da gagueira. Dessa maneira, descarta-se a hipótese da gagueira psicogênica já que a mesma teria seu início após um "evento psicológico identificável"2.

A avaliação foi realizada de forma qualitativa e quantitativa. Em relação à primeira observou-se a tipologia da disfluência, os traços associados à fala, a auto-avaliação e as observações das terapeutas. Já em relação à segunda forma de avaliação, observaram-se a velocidade de fala em leitura de textos, os tempos máximos de fonação e teste de $P A(C)$, interpretado tanto quantitativa quanto qualitativamente.

A avaliação qualitativa está presente nas quatro abordagens apresentadas nesse estudo ${ }^{5}$. A autora da vertente contextualizada adota a escuta no lugar da avaliação tradicional, atenta ao discurso do paciente compreendendo o padrão de fala em cada contexto, ou seja, como o paciente interpreta sua gagueira, bem como, o ponto de vista do interlocutor. Afirma, ainda, que a avaliação é parte integrante e ocorre de maneira constante na terapia ${ }^{3}$. Neste caso, a escuta tornou-se por vezes dificultada pelo comportamento do paciente, que inicialmente mostrava-se retraído.

A avaliação realizada por observação da terapeuta durante os atendimentos que se seguiram mostrou-se de grande valor tendo em vista que, a partir dos sintomas apresentados abordaram-se estratégias que permitiram ao paciente auto-avaliarse em relação à tensão, movimentos associados e tipologia da disfluência gerando, no mesmo, um estímulo a ser monitorado e quando possível, corrigir os comportamentos inadequados.

As habilidades de fala - tempos máximos de fonação e velocidade de fala, foram avaliadas objetivando, em terapia, o modelamento da fluência, conforme abordagem psicolingüística da fluência, na qual se preconiza a redução da velocidade de fala para uma produção articulatória mais suave e para compensar a instabilidade apresentada pelo mecanismo motor de fala do sujeito gago'. E, segundo a abordagem neurolinguística e motora da gagueira, visa-se a promoção da fluência alcançada pela suavização ao início da emissão, já que os indivíduos gagos não apresentam uma prontidão para a atividade de fala, favorecendo com isto, a ocorrência da disfluência e uma latência maior para início da mesma ${ }^{5-15}$.

O paciente foi avaliado, ainda, quanto ao $\mathrm{PA}(\mathrm{C})$, pois este teste é complementar à avaliação fonoaudiológica, partindo do princípio em que há relação entre a fluência da fala e alterações de $\mathrm{PA}(\mathrm{C})$ visando utilizar também, em terapia, técnicas para melhorar as habilidades alteradas do $\mathrm{PA}(\mathrm{C})$. $O$ resultado apresentado pelo paciente revela um melhor desempenho da orelha direita em testes de escuta direcionada?

A terapia em questão objetivou a realização de atividades relacionadas às suas necessidades. Ao realizar o embasamento teórico, com a finalidade de aprofundar os conhecimentos para o atendimento fonoaudiológico, a primeira autora deparou-se com as quatro abordagens. Num primeiro momento, o estudo objetivou o levantamento dos aspectos referentes a essas abordagens que poderiam contribuir para o tratamento.

As quatro abordagens citadas e as terapias realizadas possuem pontos em comum (figura 3 ): 


\begin{tabular}{|l|l|}
\hline PONTOS TRABALHADOS EM TERAPIA & ABORDAGENS EM COMUM \\
\hline Treinamento das habilidades de fala & $\begin{array}{l}\text { Psicolingüística da fluência; } \\
\text { Neurolinguística e motora da gagueira. }\end{array}$ \\
\hline Relaxamento corporal & $\begin{array}{l}\text { Neurolinguística e motora da gagueira; } \\
\text { Vertente contextualizada; } \\
\text { Fenomenológica da fluência. }\end{array}$ \\
\hline Promoção da fluência & $\begin{array}{l}\text { Neurolinguística e motora da gagueira; } \\
\text { Psicolingǘstica da fluência; } \\
\text { Fenomenológica da fluência. }\end{array}$ \\
\hline Imagem de falante & $\begin{array}{l}\text { Vertente contextualizada; } \\
\text { Fenomenológica da fluência. }\end{array}$ \\
\hline Orientação à família & $\begin{array}{l}\text { Neurolinguística e motora da gagueira; } \\
\text { Vertente contextualizada. }\end{array}$ \\
\hline Aceitação da gagueira & $\begin{array}{l}\text { Vertente contextualizada; } \\
\text { Fenomenológica da fluência. }\end{array}$ \\
\hline
\end{tabular}

Figura 3 - Relação entre os aspectos trabalhados em terapia e as abordagens

Ao observar no quadro acima as estratégias utilizadas e a correlação com as respectivas abordagens, ressalta-se que as maiores semelhanças ocorrem entre a abordagem neurolinguística e motora da gagueira e a psicolingüística da fluência que se apóiam na concepção cientifica clássica e entre a vertente contextualizada e fenomenológica da fluência que analisam a subjetividade do sujeito ${ }^{5}$.

Para alcançar os resultados obtidos ao final do tratamento foram realizadas atividades de relaxamento corporal focando a redução da tensão e consequente suavização da emissão e readequação da postura, controle da respiração e regulação do ritmo, visando a melhora do aproveitamento da capacidade vital durante a fala, treinamento rítmico, prosódico e expressão corporal ${ }^{5}$. O paciente recebeu orientações para que a realização dos exercícios citados ocorresse diariamente. Para isso, confeccionou-se um caderno de atividades, construído a cada terapia para que o paciente buscasse subsídios quando necessário. As sessões encontravam-se pré-estruturadas contendo a realização dos exercícios de relaxamento e habilidade de fala, seguida de atividades que viessem ao encontro da demanda e da evolução apresentada pelo paciente.

Dentre as diversas atividades, destacam-se as gravações em vídeo que objetivaram conscientizar o paciente e comprometê-lo com o tratamento. Dessa forma, as atividades de cunho lúdico permitiram fortalecer o vínculo entre o paciente e a terapeuta, resultando em uma melhora na auto-estima. A imagem de falante foi construída a partir da valorização dos aspectos positivos apresentados pelo mesmo, como o interesse e o conhecimento nas áreas da ciência e história, revelando-se um adolescente culto, estudioso e inteligente. Apesar disso, o paciente demonstrava possuir consciência sobre a sensação de limitação que a gagueira impõe, visto que, ao considerar a fluência como padrão de normalidade, obviamente que a disfluência representava a anormalidade. A normalidade, no entanto, não é homogênea, mas constituída de diversidades e singularidades devido às particularidades de cada sujeito, fato este que deve ser apontado e sinalizado no contexto terapêutico ${ }^{19}$.

A imagem que o paciente construiu deixouo confiante, influenciando-o em relação à sua fala. Segundo o questionário respondido por J., o mesmo não possui sentimentos de inferioridade em relação aos seus colegas e nem se sente tratado com discriminação devido a sua fala disfluente.

Desde os primeiros atendimentos, J. foi conscientizado da presença constante da gagueira em sua vida e que o mesmo necessita de orientação para buscar melhores estratégias de lidar com o distúrbio apresentado.

O sujeito e o objeto (gagueira) são inseparáveis e por isso a gagueira deve ser vista como parte integrante do sujeito e, com isso, deve-se manter o cuidado do corpo e da disfluência que se manifesta neste corpo buscando as mudanças necessárias almejando a fluência ${ }^{4}$.

O paciente mostrou maior adaptação às atividades propostas pelas abordagens neurolinguística e motora da gagueira e psicolingüística da fluência, devido as mesmas serem objetivas e pontuais, atingindo o foco que o fez buscar o atendimento, qual seja, a disfluência. Porém, em nenhum momento 
descartou-se os aspectos subjetivos trazidos pelo paciente já que o motivo que faz com que o paciente procure um atendimento profissional é a busca pela qualidade de vida, neste caso, gerada a partir da melhora da fluência. Contudo, é evidente que a integração das abordagens propostas combinadas ao desejo do paciente contribuíram para a evolução do mesmo.

Em virtude do resultado apresentado na última avaliação do $\mathrm{PA}(\mathrm{C})$ propõe-se, para a continuidade do tratamento, a realização do treinamento auditivo das habilidades de resolução temporal para a orelha esquerda $^{10}$. O processamento auditivo temporal refere-se à percepção de eventos acústicos no domínio do tempo, sendo uma habilidade relevante para a fala inserida no $\mathrm{PA}(\mathrm{C})$ que envolve outras habilidades e refere-se à eficiência e a efetividade com que o sistema nervoso central organiza a informação auditiva. A resolução temporal, por sua vez, é uma das habilidades do processamento auditivo temporal, definida como a percepção de um curto intervalo de tempo (2 a 3 milissegundos) em que o indivíduo pode discriminar dois sinais auditivos ${ }^{23}$.

Conforme dados colhidos do prontuário do paciente, a terapia anterior (2005/2006) focou-se no treinamento das habilidades do $\mathrm{PA}(\mathrm{C})$ alteradas: decodificação, integração e organização de saída, sendo estas relacionadas à maturação e aos aspectos mais gerais e não aos aspectos específicos do processamento auditivo temporal.

De acordo com a evolução no atendimento, foi sugerido um período de monitoramento, inicialmente com encontros quinzenais, passando a períodos mensais, porém o paciente não retornou.

A terapia para indivíduos que gaguejam deve ser formulada a partir das necessidades apresentadas pelo paciente, na qual, terapeuta e paciente buscarão o mesmo objetivo e o tempo de terapia será definido a partir dos critérios estabelecidos por ambos.

Ao terapeuta é importante realizar uma escuta atenta e sem antecipações do que será dito pelo sujeito, pois, somente desta forma, será possível identificar a demanda (necessidade) de seu paciente para, a partir deste ponto, definir estratégias. J. poucas vezes expressou seus sentimentos em relação à gagueira, porém deixou claro os objetivos pelos quais buscou a terapia fonoaudiológica e seu desejo de melhorar. Por meio da vivência das atividades realizadas mostrou seu interesse em momentos determinados. Diante disso, destaca-se a relevância da observação das necessidades para direcionamento da terapia.

\section{CONCLUSÃO}

O presente estudo objetivou a discussão das abordagens apresentadas no atendimento de um paciente com gagueira.

Durante o processo, o paciente referiu maior adaptação às atividades propostas pelas abordagens neurolinguística e motora da gagueira e psicolingüística da fluência por serem mais objetivas.

Convém ressaltar que os aspectos subjetivos, considerados ao longo do processo, foram de grande relevância para a evolução terapêutica. Foi instaurado um espaço terapêutico que permitiu ao paciente direcionar a terapia conforme a aceitação e aplicação prática em seu dia-a-dia, revelando por meio dos resultados as condutas mais efetivas, ou seja, aquelas que contribuíram mais diretamente com a melhora em sua qualidade de vida.

Ao fonoaudiólogo cabe identificar não só a queixa apresentada pelo paciente, mas também sua demanda, pois desta forma a direção do tratamento toma outros rumos e pode ser rediscutida a qualquer momento, em função de novas demandas. 


\begin{abstract}
Background: stuttering may currently have different definitions according to the approach advocated by the authors to substantiate such a disorder. The paper aims to discuss such approaches in the therapy of the case, applying its therapeutic techniques and adapting them according to the context at issue and take the individual to activities, promoting the development of goals, procedures and techniques used in the stuttering therapy. Procedures: a longitudinal study of a patient being 14 year old, met on two occasions: in 2005-2006, the year he was discharged with an indication for monitoring, and 2008/2009 season in returning to treatment due to relapse. In the study, the different approaches considered were: psycholinguistics fluency, stuttering and motor neurolinguistics, contextual and phenomenological aspects of stuttering. Results: in the evolution, there was a considerable decrease in stuttering and compensatory movements, as well as appropriate behavior and attitude and improved socialization. Conclusion: the study on the approaches considered in the therapy enabled the performance of the service that hit the targets. In addition, the patient contributed for directing the therapy as per the acceptance and application in his life, revealed by the results of more effective behaviors, contributing to the quality of life and evolution.
\end{abstract}

KEYWORDS: Stuttering; Language Therapy; Language; Speech Therapy; Case Studies; Communication

\section{REFERÊNCIAS}

1. Schiefer AM. Abordagem psicolingüística da fluência. In: Ferreira LP, Befi-Lopes D, Limongi SCO. (Org.). Tratado de Fonoaudiologia. São Paulo: Roca, 2004. p. 1035-9.

2. Andrade CRF. Abordagem neurolinguística e motora da gagueira. In: Ferreira LP, Befi-Lopes D, Limongi SCO (Org). Tratado de Fonoaudiologia. São Paulo: Roca, 2004. p. 1001-13.

3. Friedman S. Fluência: um acontecimento complexo. In: Ferreira LP, Befi-Lopes D, Limongi SCO. (Org). Tratado de Fonoaudiologia. São Paulo: Roca, 2004. p. 1027-34.

4. Meira I. Abordagem fenomenológica da fluência. In: Ferreira LP, Befi-Lopes D, Limongi SCO. (Org.). Tratado de Fonoaudiologia. São Paulo: Roca, 2004. p. 1017-25.

5. Moraes RA, Nemr KA Gagueira sob diferentes olhares: análise comparativa das abordagens de quatro autoras. CEFAC. 2007; 9(3): 308-18.

6. Andrade NA, Gil D, Schiefer AM, Pereira LD. Avaliação comportamental do processamento auditivo em indivíduos gagos. Pró-Fono Rev atual cient. 2008. 20(1):43-8.

7. Andrade NA, Gil D, Schiefer AM, Pereira LD. Processamento auditivo em gagos: análise das orelhas direita e esquerda. Rev Soc Bras Fonoaudiol. 2008. 13(1): 20-9.

8. Andrade CRF, Sassi FC, Matas CG, Neves IF, Martins, VO. Potenciais evocados auditivos pré e pós-tratamento em indivíduos gagos: estudo piloto. Pró-Fono Rev atual cient. 2007. 19(4):401-5.

9. Kikuchi Y, Ogata K, Umesaki T, Yoshiura T, Kenko M, Hirano Y, Okamoto T, Komune S, Tobimatsu S. Spatiotemporal signatures of na abnormal auditory system in stuttering. Neuorimage. 2011.55(3):891-9. 10. Jutras B, Lagacé J, Lavigne A, Boissonneault A, Lavoie C. Auditory processing disorders, verbal disfluency, and learning dificulteis: a case study. Int J Audiol. 2007. 46(1):33-8.

11. Hampton A, Weber-Fox C. Non-linguistic auditory processing in stuttering: evidence from behavior and event-related brain potentials. J Fluency Disord. 2008. 33(4): 243-73.

12. Andrade CRF, Sassi FC, Juste FS, Ercolin B. Qualidade de vida em indivíduos com gagueira desenvolvimental persistente. Pró-Fono Rev atual cient. 2008. 20(4):219-24.

13. Chun RYS, Mendes CD, Yaruss JS, Quesal RW. The impact of stuttering on quality of life of children and adolescents. Pró-Fono Rev atual cient. 2010. 22(4):567-70.

14. Arcuri CF, Osborn E, Schiefer AM, Chiari BM. Taxa de elocução de fala segundo a gravidade da gagueira. Pró-Fono Rev atual cient. 2009. 21(1):45-50.

15. Andrade CRF, Sassi FC, Juste FS, Meira MIM. Atividades de fala e não-fala em gagueira: estudo preliminar. Pró-Fono Rev atual cient. 2008. 20(1):67-70.

16. De Nil LF, Beal DS, Lafaille SJ, Kroll RM, Crawley AP, Gracco VL. The effects of simulated 
stuttering and prolonged speech on the neural activation patterns of stuttering and nonstuttering adults. Brain Lang. 2008. 107(2): 114-23.

17. Howell P. Behavioral effects arising from the neural substrates for atypical planning and execution of Word production in stuttering. Exp. Neurol. 2010. 225(1): 55-9.

18. Hennessey NW; Nang CY, Beiby JM. Speeded verbal responding in adults who stutter: are there déficits in linguistic ecoding? J Fluency Disord. 2008. 33(3):180-202.

19. Friedman S. Imagem de falante e qualidade de vida: uma perspectiva ética para a terapia fonoaudiológica. Saúde em revista. 2003. 5(9):7-11.

20. Prasse JE, Kikano GE. Stuttering: an overview. Am Fam Physician. 2008.77(9):1271-6.

21. Kaganovich N, Wray AH, Weber-Fox C. Non-linguistic auditory processing and working memory update in pré-school children who stutter: an electrophysiological study. Dev. Neuropsychol. 2010. 35(6): 712-36

22. Oliveira CMC, Souza HAS, Santos AC, Cunha $D$, Giacheti CM. Fatores de risco na gagueira desenvolvimental familial $e$ isolada. CEFAC. ahead of print, pp. 0-0 Available from: <http:// www.scielo.br/scielo.php?script=sci_arttext\&pid= $\mathrm{S} 1516-18462010005000116 \& \mathrm{lng}=\mathrm{e}$ \& $\mathrm{nrm}=\mathrm{iso}>$. Epub Oct 29, 2010. ISSN 1516-1846. doi: 10.1590/ S1516-18462010005000116.

23. Samelli AG, Schochat E. Processamento auditivo, resolução temporal e teste de detecção de gap: revisão da literatura. CEFAC.2008. 10(3):369-77.

24. Chang $\mathrm{S}$, Erickson $\mathrm{KL}$, Ambrose NG, Hasegawa-Johnson MA, Ludlow C. Brain anatomy differences in childhood stuttering. Neuroimage. 2008. 39(3):1333-44.

Endereço para correspondência:

Maria Inês Dornelles da Costa Ferreira

Rua Luiz Afonso 158 Apto 702 - Cidade Baixa

Porto Alegre - RS

CEP: $90050-310$

E-mail: costa.ferreira@terra.com.br 